\title{
Crescer a brincar nos espaços verdes urbanos
}

\section{Lídia Machado dos Santos ${ }^{\mathrm{a}}$, Bruno Martins ${ }^{\mathrm{b}}$}

${ }^{a}$ Escola Superior de Educação de Bragança, Instituto Politécnico de Bragança, Bragança, Portugal lidia.flavie@ipb.pt, ${ }^{b}$ Escola de Ciências Agrárias e Veterinárias, Universidade de Trás-os-Montes e Alto Douro, Vila Real, Portugal, brunomartins@utad.pt

\begin{abstract}
Resumo
Vivemos num tempo em que as cidades aumentam a sua população $e$ densificam o espaço urbano, o que, geralmente, condiciona também o contacto com a natureza. Desta forma, as crianças crescem hoje distanciadas da natureza, o que traz consequências para a aprendizagem acerca do meio natural, nomeadamente aquela que ocorre pela sua experimentação e observação direta, muitas vezes enquanto brincam. Os espaços verdes urbanos (EVU) prestam um serviço neste âmbito aos habitantes das cidades, ao qual, muito dificilmente se encontra alternativa. Assim, o presente trabalho explora os EVU enquanto espaços que permitem brincar ao ar livre e, simultaneamente, a aprendizagem, na qual a criança explora o meio natural, conhece a fauna e a flora da região, bem como aprende jogos tradicionais, entre outros. Elaboraram-se para isso inquéritos por questionário anónimo, destinados a alunos do $1 .{ }^{\circ}$ Ciclo do Ensino Básico de um Agrupamento de Escolas da cidade de Bragança e seus encarregados de educação, nos quais se questionam ambas as gerações acerca do uso dos espaços verdes/meio natural para brincar. O trabalho conclui acerca da importância dos EVU enquanto locais que disponibilizam maior espaço para brincar e contacto com a natureza, bem como são também espaços de aprendizagem e sociabilização. Conclui-se ainda acerca das diferentes vivências entre gerações e dos EVU serem utilizados para brincadeiras promotoras do exercício físico e mais "tradicionais".
\end{abstract}

Palavras-chave: Brincar, aprender, espaços verdes urbanos, serviços ecossistémicos.

\section{Introdução}

Durante o ato de brincar a criança interage com o mundo em geral, o que propicia o seu desenvolvimento e aprendizagem através da sociabilização, vivências lúdicas e 
representações simbólicas que são essenciais para a formação da sua personalidade e autonomia (Dantas, 2017). O tempo de brincadeira desenvolve também na criança as capacidades de raciocínio e reflexão, bem como o sentido de responsabilidade e a moralidade (Teixeira, 2017). Assim, é importante que a criança brinque para que desenvolva as suas capacidades, sejam elas motoras ou cognitivas, uma vez que a brincadeira (preferencialmente em grupo ou em pares) poderá experienciar aprendizagens diversas que marcarão e desenvolverão positivamente, estamos certos, a criança.

Para além de inúmeros serviços ecossistémicos que fornecem, os espaços verdes urbanos (EVU) proporcionam espaço e momentos de recreio para a criança. Distinguem-se por oferecerem maior espaço livre para brincar, permitirem brincadeiras diferentes dos jogos tecnológicos que cada vez mais a criança possui e, sobretudo, brincadeiras com caráter mais físico, também hoje menos comuns em comparação com as brincadeiras da criança do passado (Larson, Whiting, Green, \& Bowker, 2014; Herman, Sabiston, Mathieu, Tremblay, \& Paradis, 2014; Ma, Le Mare, \& Gurd, 2015; Andrusaityte, Grazuleviciene, Dedele, \& Balseviciene, 2020). Brincar em EVU assume, assim, importância nas cidades. Além disso, Andrusaityte et al. (2020) observaram no seu estudo a existência de uma associação positiva entre o uso de EVU e a redução de riscos gerais para a saúde em geral e a saúde mental em particular da criança. Esta prática de exercício físico, promovida por determinados jogos e brincadeiras que a ela conduzem, pode ainda, para além dos benefícios ao nível da saúde, melhorar o desempenho escolar da criança enquanto estudante, nomeadamente uma maior atenção e concentração nas tarefas escolares (Ma et al., 2015). Quando a criança brinca num EVU é importante para o seu desenvolvimento intelectual consentir que explore todo o espaço e permitir ainda que crie as suas próprias brincadeiras, inclusive com materiais e objetos que encontre no próprio local, não a confinando, portanto, a um único lugar de que pode ser exemplo o parque infantil, ou limitando simplesmente as suas brincadeiras de forma geral (del Pulgar, Anguelovski, \& Connolly, 2020).

\section{Objetivos}

O presente trabalho visa estudar o papel dos EVU da cidade de Bragança (cidade do nordeste português), sobretudo os que são utilizados por crianças do $1 .^{\circ}$ Ciclo do Ensino Básico (1. $\left.{ }^{\circ} \mathrm{CEB}\right)$, enquanto espaços de brincadeira e consequente aprendizagem. Além disso, pretende-se ainda averiguar o papel que estes espaços tiveram, relativamente às mesmas questões, na geração dos seus pais/encarregados de educação. 


\section{Metodologia}

Para a realização do presente estudo distribuíram-se inquéritos por questionário anónimo a alunos do $1 .{ }^{\circ} \mathrm{CEB}$ e seus encarregados de educação de um estabelecimento de ensino do $1 .^{\circ}$ CEB privado (Escola Dr. Diogo Albino Sá Vargas de Bragança). Os questionários consistiam sobretudo em questões fechadas de escolha múltipla, mas possuíam também algumas questões abertas para que os inquiridos pudessem expressar livremente a sua opinião. Os questionários fornecidos aos alunos foram preenchidos durante o horário letivo, enquanto que os encarregados de educação os preencheram em casa. Salienta-se ainda que, apesar de os questionários terem sido desenhados para serem preenchidos pelos próprios alunos (crianças do $1 .^{\circ} \mathrm{CEB}$ ), optou-se por não incluir os alunos do $1 .^{\circ}$ ano de escolaridade e respetivos encarregados de educação, uma vez que se entendeu que a escolaridade (capacidade de leitura e interpretação) dos primeiros não seria suficiente para poderem realizar sozinhos e anonimamente o preenchimento do questionário.

Ambos os questionários (alunos e encarregados de educação) focaram os mesmos pontoschave de forma a perceber a vivência, nomeadamente do brincar, num espaço verde desta geração quando comparada com a dos encarregados de educação, embora naturalmente adaptando as questões a cada grupo de inquiridos.

Após recolhidos os questionários em suporte papel, os mesmos foram convertidos para formato digital editável de forma a poderem ser manipulados em software estatístico. $\mathrm{O}$ tratamento dos dados das questões fechadas foi realizado através de estatística descritiva, enquanto os dados provenientes das questões abertas foram sujeitos a análise prévia de conteúdo e respetiva categorização. Os dados são apresentados através da frequência absoluta e percentagem.

\section{Resultados}

\subsection{Caraterização dos respondentes}

Inquiriu-se um total de quarenta (40) alunos. Desse total de alunos deve dizer-se que $20 \%$ frequentavam o $2 .^{\circ}$ ano de escolaridade, $40 \%$ o $3 .^{\circ}$ ano de escolaridade e os restantes $40 \%$ frequentavam o $4 .^{\circ}$ ano. As suas idades variavam entre os 7 e os 11 anos. Por outro lado, verificou-se que apenas trinta (30) encarregados de educação responderam ao questionário.

\subsection{Brincadeiras nos espaços verdes urbanos}

A Fig. 1. representa a azul claro as brincadeiras que os encarregados de educação tinham quando eram crianças num parque ou jardim. Por sua vez, a azul-escuro representam-se as 
brincadeiras que os alunos inquiridos têm atualmente em parques e jardins. Ressalva-se ainda que as brincadeiras/jogos menos frequentes entre os inquiridos foram agrupados em "outros não comuns entre os inquiridos".
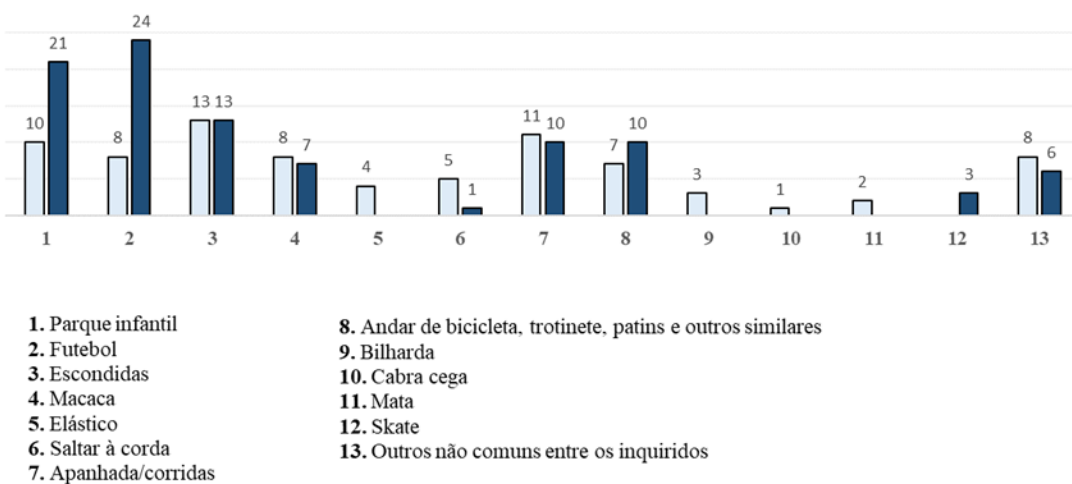

8. Andar de bicicleta, trotinete, patins e outros similares

9. Bilharda

10. Cabra cega

11. Mata

12. Skate

13. Outros não comuns entre os inquiridos

口Encarregados Educação $\square$ Alunos

Fig. 1 Brincadeiras que encarregados de educação tinham e que alunos têm em parques/jardins. Fonte: Elaboração própria

Enquanto no passado, isto é, na época em que os atuais encarregados de educação eram crianças, os parques e os jardins eram frequentemente locais de jogos como as "escondidas" (13) ou o "mata" (11), na atualidade, o futebol (24) e o parque infantil (21) dominam as brincadeiras. Não obstante, salvaguarda-se o facto de o parque infantil ser também já importante na época dos encarregados de educação (10), uma vez que se encontra entre as maiores frequências absolutas de resposta.

Verifica-se que "jogos tradicionais" e populares entre as crianças de então - o "elástico", o "saltar à corda", a "bilharda", a "cabra cega" e o "mata" - ocupavam parte das brincadeiras dos atuais encarregados de educação enquanto crianças, mas perderam expressividade, ganhando força outros que, entretanto, se tornaram mais populares e de que é exemplo o skate. Assim, as respostas dos encarregados de educação mostram uma maior diversidade de jogos que as crianças de então tinham, comparadas com as que os seus filhos têm hoje. Os alunos inquiridos, quando vão a um parque ou jardim, preferem geralmente jogos que requerem bens de consumo ou equipamentos, como o futebol, o parque infantil, andar de bicicleta, andar de trotinete, andar de patins, etc., enquanto os seus encarregados de educação privilegiavam, na generalidade, jogos que apenas requeriam imaginação e/ou o que o próprio espaço verde fornecia, resultando numa maior diversidade de brincadeiras. Diversos alunos referiram nas questões abertas ter aprendido a jogar futebol, andar de skate, etc., precisamente nos EVU. 
Observa-se que as brincadeiras relacionadas com os parques infantis e com o futebol foram as que mais aumentaram comparativamente à geração dos encarregados de educação, tendo-se mantido as restantes (com a exceção da bicicleta), diminuído ou até nem sequer sido mencionadas pelos alunos.

\subsection{A importância de brincar nos espaços verdes urbanos}

A Fig. 2. ilustra os motivos pelos quais os encarregados de educação consideram importante que as crianças brinquem em EVU e, por outro lado, também os motivos pelos quais os alunos consideram os EVU bons locais para brincar. Ressalva-se que na questão era possível indicar mais do que um motivo.
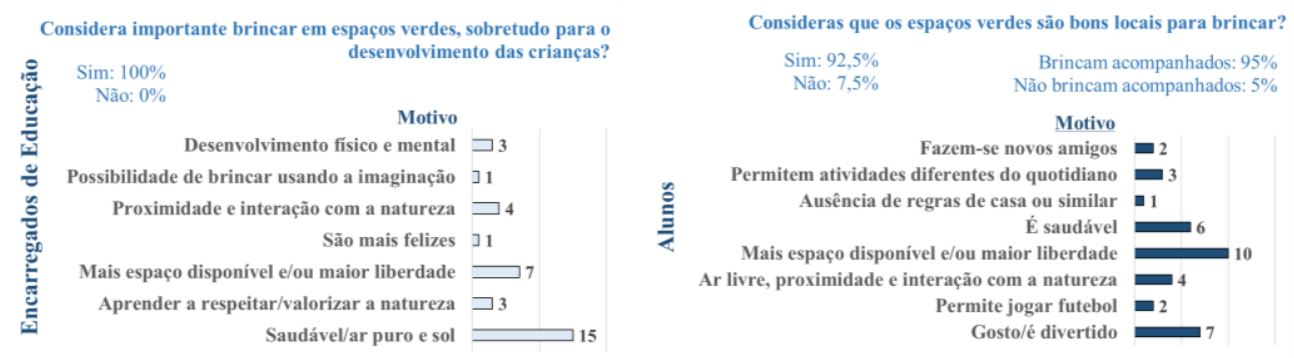

Fig. 2 Brincar em espaços verdes urbanos.

Fonte: Elaboração própria

Observa-se que todos os encarregados de educação inquiridos sem exceção (100\%) consideram ser importante para as crianças brincar em EVU. Os motivos apontados pelos encarregados de educação para justificar a sua afirmação prendem-se, na sua maioria, com o facto de os EVU estarem associados à salubridade, ao ar puro e ao sol (15). A existência de mais espaço disponível e/ou maior liberdade foi também um dos aspetos mais apontados (7). Além destes, os encarregados de educação indicaram também outros motivos como a proximidade e a interação com a natureza (4), o desenvolvimento físico e mental (3), aprender a respeitar/valorizar a natureza (3), a possibilidade de brincar usando a imaginação (1) e o facto de as crianças serem mais felizes nos EVU (1).

Por outro lado, também uma grande percentagem de alunos (92,5\%) considera que os EVU são bons locais para brincar, contra 7,5\% que não o considera. Entre os motivos pelos quais os alunos julgam que são bons espaços para brincar, aquele que mais se destacou foi o facto de existir mais espaço disponível e/ou maior liberdade (10). Porém, também com relativa quantidade de respostas destaca-se o facto de os alunos gostarem e/ou acharem divertido (7) brincar num EVU, bem como a salubridade (6) destes espaços (também já apontada pelos 
encarregados de educação). Outras razões foram ainda apontadas pelos alunos cuja resposta foi afirmativa, embora com menor frequência absoluta.

Verificou-se ainda que os EVU têm um papel importante na sociabilização das crianças entre si, uma vez que $95 \%$ dos alunos inquiridos afirmaram brincar acompanhados quando brincam num espaço verde.

\section{Discussão dos resultados}

Tal como outras mudanças que ocorreram na sociedade, também as brincadeiras que as crianças têm nos parques infantis se alteraram face à geração dos seus encarregados de educação. Assim, enquanto os atuais encarregados de educação preferiam, sobretudo, jogos que não careciam de bens de consumo, as crianças da atualidade privilegiam brincadeiras que os necessitam e de que são exemplo o futebol e o skate. Não obstante, verifica-se também que os parques e jardins continuam a propiciar entre as crianças brincadeiras que promovem o exercício físico e o desenvolvimento intelectual, como o desenvolvimento da imaginação. Salienta-se que mesmo espaços como o parque infantil muito referidos nas brincadeiras, quer pelos encarregados de educação, quer pelos alunos, podem possuir equipamentos destinados ao desenvolvimento físico, mas também ao desenvolvimento intelectual.

A maior densidade que se faz sentir nos territórios urbanos e que se deve ao crescimento da população (Glaeser \& Henderson, 2017) propicia a carência de espaços abertos. Os parques e jardins têm aqui um papel crucial na medida que permitem a prática de certas atividades que requerem maior espaço. Este é o caso apresentado por alguns alunos que usam os parques e jardins para jogar futebol, andar de skate ou patins e que inclusive aprenderam a praticar estas atividades nos EVU. Girma, Terefe, and Pauleit (2019) acrescentam ainda que se o desenho dos parques e jardins possibilitar a prática dessas atividades, em conjunto com a sua proximidade à habitação dos utilizadores, a utilização desses EVU será maior. Além disso, tem-se verificado que a proximidade dos EVU apresenta também um efeito direto sobre a saúde e bem-estar da população em geral (Dadvand et al., 2016; O'CallaghanGordo et al., 2018; O’Callaghan-Gordo et al., 2020), pelo que é multiplamente benéfico. Desta forma, é importante investir em EVU de proximidade que possuam dimensão suficiente para a prática das referidas atividades.

Embora estes jogos (futebol, skate, bicicleta, patins, etc.) promovam o exercício físico - o que por si só é já benéfico, uma vez que se baseiam em objetos trazidos de casa pela criança como a bola, os patins ou a bicicleta, - podem também evitar que a criança interaja com a natureza (del Pulgar et al., 2020). Este efeito é oposto ao interesse mostrado pelos 
encarregados de educação que pretendem a existência de um maior número de aulas em EVU com o intuito de que os alunos possam interagir e conhecer o meio natural. Outra questão apontada por del Pulgar et al. (2020), e que pode desmotivar a interação com a natureza, é, ironicamente, o aspeto mais cuidado que certos EVU apresentam e que são imediatamente conotados com as palavras "não mexer" ou "não pisar", considerando então os pais e os alunos que esses espaços, árvores, etc., não são para interagir e que apenas se encontram na cidade por questões estéticas. Tivemos também esse relato por parte de alunos aquando o preenchimento dos inquéritos que, consideraram que os EVU não são um bom local para brincar, porque, se o fizessem, "estragavam" as plantas. Porém, devemos lembrar-nos de que hoje os EVU representam um papel importante visto que são muitas vezes o único contacto que a criança urbana tem com o mundo natural e é também por isso importante que possa com eles interagir, não só pela questão da(s) aprendizagem/aprendizagens, mas também para desenvolverem defesas no seu organismo, entre outros aspetos.

\section{Conclusões}

Os EVU desempenham um papel importante na vida das famílias, uma vez que propiciam o contacto com a natureza e estadia ao ar livre, bem como permitem que as crianças tenham brincadeiras que promovem o exercício físico, estimulando, consequentemente, o seu desenvolvimento físico. Verificou-se que os EVU estimulam também o desenvolvimento intelectual, uma vez que as crianças tendem a ter brincadeiras nestes espaços que suscitam a imaginação e a linguagem, muito devido a todo o espaço disponível e aos recantos e lugares "construídos" pela natureza.

Verificou-se que nos nossos dias as brincadeiras que as crianças inquiridas têm nos EVU requerem a utilização de bens de consumo, contrariamente àquelas referidas pelos seus encarregados de educação que não os necessitavam e que até os desconheciam. Não obstante, ambas as gerações mencionaram o espaço livre para brincar e o contacto com a natureza como mais-valia destes espaços.

O brincar nos EVU promove também a aprendizagem. Além da interação com a natureza referida por alguns alunos, que por si só promove a exploração e a aprendizagem por observação direta, constatámos também que diversos alunos aprenderam a jogar futebol, andar de skate, patins, etc., precisamente nos EVU. Além disso, verificámos que os EVU são ao mesmo tempo um local que possibilita brincar utilizando jogos "tradicionais" como a "cabra-cega" ou as "escondidas", o que propicia a sua transmissão entre gerações. 
Os EVU promovem a sociabilização das crianças entre si, uma vez que a grande maioria dos alunos inquiridos brinca acompanhada nestes espaços.

\section{Referências}

Dadvand, P., Bartoll, X., Basagaña, X., Dalmau-Bueno, A., Martinez, D., Ambros, A., ... \& Nieuwenhuijsen, M. J. (2016). Green spaces and general health: roles of mental health status, social support, and physical activity. Environment international, 91, 161-167.

Dantas, G. P. (2017). O brincar no desenvolvimento infantil. São Paulo: Senac.

del Pulgar, C. P., Anguelovski, I., \& Connolly, J. (2020). Toward a green and playful city: Understanding the social and political production of children's relational wellbeing in Barcelona. Cities, 96, 102438.

Girma, Y., Terefe, H., \& Pauleit, S. (2019). Urban green spaces use and management in rapidly urbanizing countries:-The case of emerging towns of Oromia special zone surrounding Finfinne, Ethiopia. Urban forestry \& urban greening, 43, 126357.

Glaeser, E., \& Henderson, J. V. (2017). Urban economics for the developing World: An introduction. Journal of Urban Economics, 98, 1-5.

Herman, K. M., Sabiston, C. M., Mathieu, M. E., Tremblay, A., \& Paradis, G. (2015). Correlates of sedentary behaviour in 8-to 10-year-old children at elevated risk for obesity. Applied Physiology, Nutrition, and Metabolism, 40(1), 10-19.

Larson, L. R., Whiting, J. W., Green, G. T., \& Bowker, J. M. (2014). Physical activity of youth in non-urban parks: an observation-based assessment. Leisure/Loisir, 38(3-4), 225-232.

Ma, J. K., Le Mare, L., \& Gurd, B. J. (2015). Four minutes of in-class high-intensity interval activity improves selective attention in 9-to 11-year olds. Applied physiology, nutrition, and metabolism, 40(3), 238-244.

O'Callaghan-Gordo, C., Espinosa, A., Valentin, A., Tonne, C., Pérez-Gómez, B., Castaño-Vinyals, G., ... \& Vanaclocha-Espi, M. (2020). Green spaces, excess weight and obesity in Spain. International journal of hygiene and environmental health, 223(1), 45-55.

O'Callaghan-Gordo, C., Kogevinas, M., Cirach, M., Castaño-Vinyals, G., Aragonés, N., Delfrade, J., ... \& Capelo, R. (2018). Residential proximity to green spaces and breast cancer risk: The multicase-control study in Spain (MCC-Spain). International journal of hygiene and environmental health, 221(8), 1097-1106.

Teixeira, C. C. S. (2017). A Importância da Brincadeira no Desenvolvimento Cognitivo Infantil. Id on Line Revista Multidisciplinar e de Psicologia, 10(33), 94-102. 